\title{
The simulation of transient braking force effects for disc brake caliper bench test machine
}

\author{
Ming-Hsiung $\mathrm{Ho}^{1, \mathrm{a}}$, Chih-Yi Chang ${ }^{1, \mathrm{~b}}$, and Pin-Ning Wang ${ }^{2, \mathrm{c}}$ \\ ${ }^{1}$ Department of Mechanical Engineering, Taoyuan Innovation Institute of Technology, Jhongli, \\ 32054, Taiwan, R.O.C. \\ ${ }^{2}$ Department of Material and Fiber, Taoyuan Innovation Institute of Technology, Jhongli, 32054, \\ Taiwan, R.O.C. \\ amorrisho@tiit.edu.tw, ${ }^{b}$ changci@tiit.edu.tw, ${ }^{c}$ pnwang@tiit.edu.tw
}

\begin{abstract}
Keywords: Testing bench, Braking force, Finite element analysis, Transient force
Abstract. This study analyses a disk braking caliper bench testing machine under braking conditions, to testify its structure characteristics. The analyzed objects include rotating axes and six counterweights. The first step is to use the design software SolidWorks to build axis and counterweights models. Next, the models are transferred to the finite element analysis software ABAQUS to add boundary conditions and to conduct dynamic stress analysis. The ABAQUS simulated test machine instantly applied braking stress under rotating speed 1,300 and 2,000 RPM conditions. The results showed the maximum stress located at axis and counterweight 1 was about $200 \mathrm{MPa}$ under 1,300 RPM; it had little influence on the axis as compared with yielding stress. Under the rotation speed 2,000 RPM, the maximum stress was about $380 \mathrm{MPa}$. The maximum stress is half of yielding stress. The dynamic stress area was transfer from counterweight 1 to long diameter counterweights. So the results showed this design is safty. These design parameters can use for design check and machine manufacturing.
\end{abstract}

\section{Introduction}

It has benefit to evaluate the dynamic characteristics of machines and structures prior to fabrication. FEA models could be used to approximate "structure stiffening" effects in rotating mechanical components such as fan wheels, pump rotors, motor shafts, etc. Therefore more finite element analysis; structural analysis in today design engineering, has become an inevitable step. FEA can help designers to modify the products shortcomings, and further to improve its design, with no error experiments by the repeated trial. Having this analysis information, it brings about to achieve cost savings and improves the structure design security.

Nakazawa [1] their study results of computer simulation and vehicle test showed that the proposed control laws can eliminate the effects of a laden condition on the braking distance and can increase the degree of deceleration at which wheel lock occurs, resulting in improved vehicle attitude stability during a critical maneuver. Koizumi [2] studied on the tribology of phenolic brake piston and its correlation to brake pedal feel. Several surface designs of phenolic brake pistons were created and evaluated using modified JASO C448 bench test station. In the testing, he found the friction force between a phenolic brake piston and the piston seal differs from that of a steel brake piston. Shah [3] discussed the brake system design's challenging task due to stringent performance meeting criteria and packaging constraints with weight optimization. It explains development of disc brake system with novel brake disc during transition to switch from drum to disc brake with respect to packaging constraints, which has met all the performance in competitive price. Parth [4] proposed technique consists of using a tire model and building mathematical models in a MATLAB environment to find transient vehicle speed, which in turn provides wheel loads, frictional torque, braking power and heat flux to the brake disc as a function of time. Huang [5] and his co-workers' analysis results showed that different forms of excitation have certain effects on the performance of coupled longitudinal and transverse vibration for propulsion shafting.

The simulation work is for standard: JSAE-JASO C448 [6]. This standard specifies a bench test procedure for service brakes in disc brake caliper assemblies. The bench test machine is setup for all kind of car weights by allocated counterweights assemble. In order to verify the test bench is 
matched design requirements, two types brake force were applied to rotation shaft.

In previously research [7], the dynamic properties had been verified by model analysis. In this study, the axis dynamic analysis of vehicle braking performance test machine was conducted. Since the generated moment of inertia of the counterweight is attached on the machine axis when the axis running. Various combinations of counterweight can provide a variety of braking performance and durability testing. Due to the configuration of the axis with the counterweights, the stress and deformation effects on the operation of the axis are taken into consideration. Therefore, through the above requirements, in this research will provide machine design recommendations, and check the machine's model characteristics before the formal design and manufacture.

We hope that through the whole dynamic stress distribution situation, to understand the degree of tolerance if axis load exceeds materials properties. This study will be considered under the two speed conditions, to explore the effect of different braking force applied to the axis stress. The test machine under dynamic stress analysis to withstand transient braking force

\section{Methods}

Prior to FEA analysis, using SolidWorks CAD software building analysis models, then transform models for FEA analysis. The Computer simulation of transient stress is based on ABAQUS finite element analysis software. In this study, two rotational speeds conditions were analysis. After the final results of the post-process was demonstrated by the analysis software.

Analysis models. The analysis model with counterweights is to meet the needs of different rotational moment of inertia. It is assumed that the axis and counterweights model is homogeneous, isotropic, and continuity. The models' material is set as SCM3 and the material properties are listed in Table 1. The axis and counterweight disc dimensions from 1 to 6 are shown in Fig. 1. The meshed model has 10,320 hexahedral elements; near the axis center has 2,760 wedge-shaped elements as shown in Fig 2.

Table 1. The material properties for analysis.

\begin{tabular}{||c|c|c|c|c||}
\hline \hline Designation & \multicolumn{4}{|c|}{ Properties } \\
\hline Grade & $\begin{array}{c}\text { Young Modulus } \\
\left(\mathrm{N} / \mathrm{mm}^{2}\right)\end{array}$ & $\begin{array}{c}\text { Yield Stress } \\
\left(\mathrm{N} / \mathrm{mm}^{2}\right)\end{array}$ & $\begin{array}{c}\text { Tensile Strength } \\
\left(\mathrm{N} / \mathrm{mm}^{2}\right)\end{array}$ & $\begin{array}{c}\text { Poisson } \\
\text { Ratio }\end{array}$ \\
\hline $\begin{array}{c}\text { HT } \\
\text { (High Tesile) }\end{array}$ & 210,000 & $\geqq 686$ & $\geqq 931$ & 0.3 \\
\hline
\end{tabular}

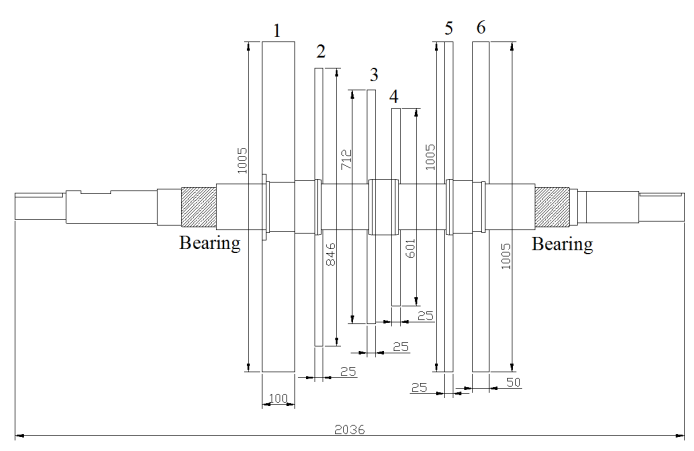

Figure 1. The axis and counterweights.

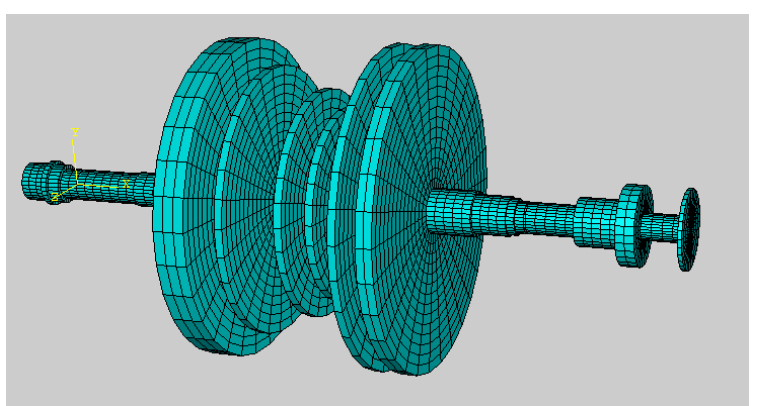

Figure 2. The model with meshed elements.

Boundary conditions. These boundary conditions are set the model to close to the actual operation conditions. The analysis model with counterweights is shown in Fig. 3. The degree of freedom of bearings support position as showed red line in Fig. 3 will be constrained to only make axial rotation, and other degrees of freedom are fixed. This axis maximum working speed is limited to 2,000 RPM.

The axis with 6 counterweights under high speed rotation and required rotational moment of inertia will be applied braking force to the brake disk instantaneously.

Theoretically, the brake pad should applied friction load at the pad center. But considering the 
most critical conditions, it was assumed that the friction force exerted on the outer edge. There are two brake pads acted together, so while there are two concentrated force as shown in Fig. 4.
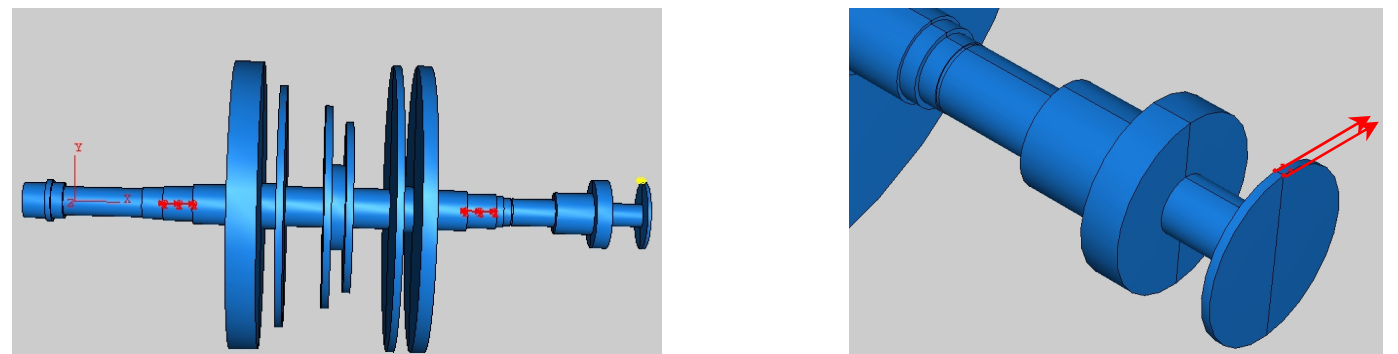

Figure 3. Analysis model and boundary conditions. Figure 4. Braking force loading position.

In full duty loading condition, the brake cylinder area is $36.42 \mathrm{~cm}^{2}$ and the maximum hydraulic pressure is $120 \mathrm{kgf} / \mathrm{cm}^{2}$. The brake pad maximum loading force $\mathrm{N}_{\mathrm{c}}$ is $42,847 \mathrm{~N}$.

$$
N_{c}=120\left(\mathrm{kgf} / \mathrm{cm}^{2}\right) \times 9.81(\mathrm{~N} / \mathrm{kgf}) \times 36.42\left(\mathrm{~cm}^{2}\right)=42,874 \mathrm{~N}
$$

And the assumed largest brake pad friction coefficient is 0.42 , therefore the maximum braking force $\mathrm{F}$ applied to brake disk is $18,00 \mathrm{y}$ N.

$$
F=\mu \times N_{c}=0.42 \times 42874=18,007 \mathrm{~N}
$$

\section{Results and Discussions}

\section{Case 1: Axis rotation speed is 1,300 RPM and braking force is $\mathrm{F}$}

Consider the rotation speed of axis and counterweights is at 1,300 RPM. The maximum braking force $\mathrm{F}=18,007 \mathrm{~N}$ was applied instantly. The dynamic stress distribution in the case of the system was shown in Fig. 5. The dynamic stress was changed gradually each time step. When the braking force applied after $1.3205 \times 10^{-4} \mathrm{~s}$, the maximum von Mises stress was about $200 \mathrm{MPa}$ at axis center of first counterweight as shown in Fig. 5(a). Next maximum von Mises stress was appeared at $5.7008 \times 10^{-4} \mathrm{~s}$, it also takes place in first axis of the counterweight. The first counterweight is the maximum weight of the 6 counterweights. The first counterweight under rotation condition has maximum moment of inertia in braking process. The instant braking force would make counterweighs' inertia force applied at axis. The counterweights inertia forces would create torque moment and applied at axis center. The counterweight 1 is the heaviest part in the analysis system and makes worst condition in short time.

Moreover, the braking force is applied gradually increases from small to maximum, rather than instantly applied. The load applied instantly would bring about the addition of the stress wave, and the maximum stress value will be up to 1.5 times the stress of gradually applied methods. Therefore, this machine is generally used in the case should be safe and secure.

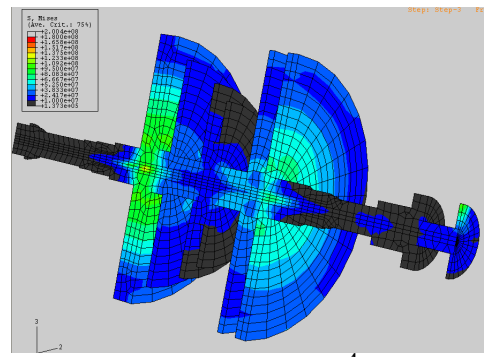

(a) $1.3205 \times 10^{-4} \mathrm{~s}$

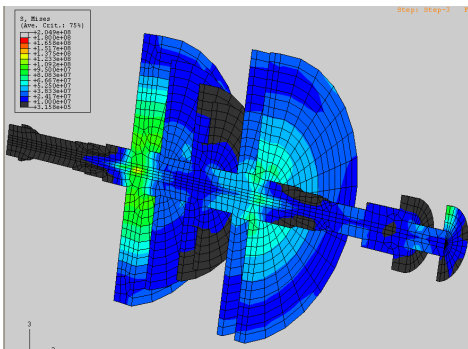

(b) $5.7008 \times 10^{-4} \mathrm{~s}$

Figure 5. The transient stress distribution at 1,300 RPM.

\section{Case 2: Axis rotation speed is 2,000 RPM and braking force is $\mathrm{F}$}

This case is simulated disc brake caliper bench test machine operated at designed speed of 2,000 RPM. The maximum braking force $\mathrm{F}=18,007 \mathrm{~N}$ is applied instantly to the disc on the right side circumference. The dynamic stress distribution is observed in Fig. 6, from this figure we can observe the greatest stress 380MPa has been moved from counterweight 1 to the section between counterweight 1 and 2, up to. But in addition, the right side near the sixth counterweight has a larger 
stress value of about 150MPa. In this design, the counterweight 1,2 and 5, 6 have long diameter circle. The longest diameter contributed square effect in moment of inertia value. In this case, maybe fatigue problem in terms of general steel shaft has a very dangerous, but still not an immediate damage, but must pay attention to possible long-term operation.

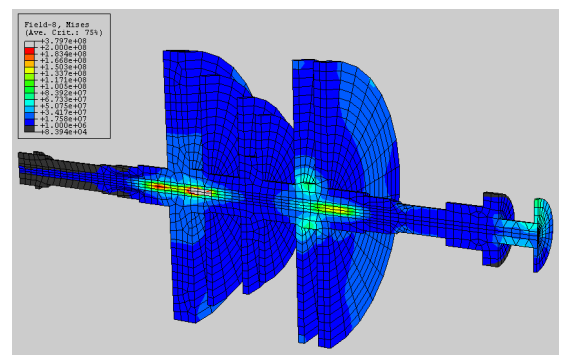

Figure 6. The transient stress distribution at 2,000 RPM.

\section{Conclusion}

The results of this study for a comprehensive rotation axis under braking force can be summarized as follows:

1. In the case of rotational axis speed was 1,300 RPM and the largest braking force was applied. The maximum stress was about $200 \mathrm{MPa}$; it had little influence on the axis as compared with yielding stress.

2. Operating at maximum speed 2,000 RPM, the largest braking force was applied. The maximum stress was about $380 \mathrm{MPa}$. The maximum stress is half of yielding stress. The dynamic stress area was transfer from counterweight 1 to long diameter counterweights.

3. Analysis conditions employed herein belong to the state of critical stress value. The stress analysis results were higher than normal operating conditions. Therefore, the results obtained herein can be regarded as the worst case results as predict.

\section{Acknowledgement}

In this paper, the research was sponsored by the Ministry of Science and Technology (Project No. MOST 104-2221-E-253-004)

\section{References}

[1] M. Nakazawa, O. Isobe, S. Takahashi and Y. Watanabe: Intern. J. Veh. Mech. and Mob. Vol. 24 (1995), p.413

[2] N. Koizumi: SAE Int. J. Mater. Manf. Vol. 7 (2014), p.1

[3] A. Shah, S. Patil, and U. Abhyankar: SAE Technical Paper 2014-01-2505 (2014)

[4] P. Parth: ASME International Design Engineering Technical Conferences Vol. 3 (2015), p. V003T01A026

[5] Q. Huang, C. Zhang, J. Liu and X. Yan: ASME 34th International Conference on Ocean, Offshore and Arctic Engineering (2015), p. V003T02A091

[6] Standard: JSAE - JASO C448: Passanger Car - Disc Brake Caliper Bench Test Procedure (1980)

[7] M.H. Ho, P.N. Wang, J.P. Yeh, P.H. Lee. and Y.X. Lai: International Symposium on Material, Energy and Environment Engineering (2015), p. 192 